Canadian

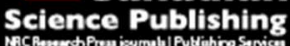

Applied Physiology, Nutrition, and Metabolism Physiologie appliquée, nutrition et métabolisme

\title{
The effects of compression garments on performance of prolonged manual labour exercise and recovery
}

\begin{tabular}{|c|c|}
\hline Journal: & Applied Physiology, Nutrition, and Metabolism \\
\hline Manuscript ID & apnm-2015-0335.R2 \\
\hline Manuscript Type: & Article \\
\hline Date Submitted by the Author: & 07-Sep-2015 \\
\hline Complete List of Authors: & $\begin{array}{l}\text { Chan, Val; University of Technology Sydney, Faculty of Health } \\
\text { Duffield, Rob; University of Technology Sydney, Faculty of Health } \\
\text { Watsford, Mark; University of Technology, Sydney, Faculty of Health }\end{array}$ \\
\hline Keyword: & $\begin{array}{l}\text { physical activity < exercise, muscle soreness < muscle soreness, recovery } \\
<\text { recovery, recovery < exercise }\end{array}$ \\
\hline
\end{tabular}


1 Title: The effects of compression garments on performance of prolonged manual labour

2 exercise and recovery

3

$4 \quad$ Running title: Compression and manual labour recovery

5

6 Authors: Val Chan ${ }^{1}$, Rob Duffield ${ }^{1}$, Mark Watsford ${ }^{1}$,

$7{ }^{1}$ Sport \& Exercise Discipline Group, Faculty of Health, University of Technology Sydney,

8 Lindfield, Australia

9

10 Corresponding author

11 Val Chan

12 University of Technology Sydney

13100 Eton Road, Lindfield NSW 2070 AUSTRALIA

$14+61423126157$

$15 \quad$ val.chan.email@gmail.com 


\section{Abstract}

2 Purpose: This study investigated the effects of wearing compression garments during and 24

$3 \mathrm{~h}$ following a 4-h exercise protocol simulating manual labouring tasks. Methods: Ten

4 physically trained male participants, familiar with labouring activities, undertook $4 \mathrm{~h}$ of work

5 tasks characteristic of industrial workplaces. Participants completed two testing sessions,

6 separated by at least one week. In the experimental condition, participants wore a full length

7 compression top and compression shorts during the exercise protocol and overnight recovery;

8 with normal work clothes worn in the control condition. Testing for serum creatine kinase

9 and C-reactive protein, handgrip strength, knee flexion and extension torque, muscle

10 stiffness, perceived muscle soreness and fatigue as well as heart rate and perceived exertion

11 (RPE) responses to 4-min cycling were performed before, following and $24 \mathrm{~h}$ after exercise.

12 Results: Creatine kinase, muscle soreness and perceived fatigue increased following the

13 exercise protocol $(\mathrm{p}<0.05)$ as did RPE to a standardised cycling warm up bout. Conversely,

14 no post-exercise changes were observed in C-reactive protein, handgrip strength, peak knee

15 flexion torque or stiffness measures $(\mathrm{p}>0.05)$. Knee extension torque was significantly higher

16 in the control condition at $24 \mathrm{~h}$ post ( $3.1 \pm 5.4 \%$ change; compression: $2.2 \pm 11.1 \%$ change),

17 although no other variables were different between conditions at any time. However,

18 compression demonstrated a moderate-large effect $(d>0.60)$ to reduce perceived muscle

19 soreness, fatigue and RPE from standardised warm up $24 \mathrm{~h}$ post. Conclusions: The current

20 findings suggest that compression may assist in perceptual recovery from manual labour

21 exercise with implications for the ability to perform subsequent work bouts.

22 Keywords: Industrial work, workability, muscle soreness, exercise recovery, occupational 23 fatigue 


\section{Abbreviations}

2 ANOVA Analysis of Variance

3 AU Arbitrary Units

4 BPM Beats Per Minute

5 BRUMS Brunel Mood State Questionnaire

$6 \mathrm{CHO} \quad$ Carbohydrates

7 CK Creatine kinase

8 COMP Compression Condition

9 CON Control Condition

10 CRP C-reactive protein

11 HR Heart rate

$12 \mathrm{HR}_{4 \min } \quad$ HR after 4 min of cycling

$13 \mathrm{~kg} \quad$ Kilogram

14 N.m Newton meter

$15 \quad \mathrm{~N} \cdot \mathrm{m}^{-1} \quad$ Newtons per meter

$16 \mathrm{RHR}_{1 \mathrm{~min}} \quad 1 \mathrm{~min}$ Recovery Heart Rate

17 RPE Rating of Perceived Exertion

$18 \mathrm{RPE}_{4 \mathrm{~min}} \quad$ Rating of Perceived Exertion after 4 min of cycling

$19 \quad \mathrm{U} \cdot \mathrm{L}^{-1} \quad$ Units per Litre 


\section{Introduction}

2 In construction and mining industries, there is a high physical demand as workers are

3 required to lift, carry, transport and manipulate heavy loads (Hartmann and Fleischer 2005;

4 Maiti 2008). Movements performed in industrial worksites are often repetitive or prolonged

5 in duration, and frequently require the individual to perform physical work in awkward, non-

6 ergonomic postures (van der Molen et al. 2005). The physical demands of these work tasks

7 can lead to fatigue and in turn impact on worker health and safety (Chang et al. 2009; Maiti

8 2008). Consequently, the term "Industrial Athlete" has been coined in recognition of the

9 physical nature and relevance of work and recovery in these occupations.

11 Psychological and physiological fatigue of workers have been identified as contributing

12 factors to workplace health and safety (Chang et. al. 2009). Whilst ergonomic and

13 mechanically assistive interventions have been developed to reduce the physical load on

14 workers (McPhee 2004; van der Molen et al. 2005), a significant amount of work is still

15 performed through manual labour on these sites (Parida and Ray 2011). Consequently, the

16 fatigue and recovery of workers is of foremost concern for injury preventions and

17 productivity in the construction and mining industries (Chang et al. 2009; Maiti 2008). Given

18 the physical nature of these industries, the application of sport-based interventions may have

19 relevance for the Industrial Athlete to assist with their workload management and recovery.

21 In the sporting context, a range of strategies are used by athletes to accelerate recovery

22 following exercise, increase their readiness to train and undertake larger training loads (

23 Bahnert et al. 2013; Gill et al. 2006). Of interest, the use of compression garments have

24 gained popularity in recent years, with the purpose of enhancing post-exercise recovery

25 through increased blood circulation and venous return (Berry and Murray 1987; Chatard et al. 
1 2004; Pruscino et al. 2013). Wearing compression garments after exercise has been found to 2 elicit smaller decrements in subsequent power and force generation (Chatard et al. 2004;

3 Jakeman et al. 2010); Kraemer et al. 2001), reduce metabolites and muscle damage marker 4 concentrations (Duffield and Portus 2007; Gill et al. 2006; Kraemer et al. 2010), and improve 5 perceptual measures of recovery and fatigue i.e., muscle soreness, vitality and readiness to $6 \quad$ train (Ali et al. 2007; Davies et al. 2009; Duffield and Portus 2007; Pruscino et al. 2013).

8 Compression garments are commonly used by the athletic population for post-exercise 9 recovery, however, to date there has been no research in the use of compression garments in a 10 physical labour context. Given the high physical demand of manual labour occupations, there 11 could be benefit in utilising compression for workplace recovery in these industries. 12 Accordingly, the aim of this study was to investigate the effect of wearing compression 13 garments on physiological and perceptual responses to, and recovery following, a prolonged 14 simulated manual labouring protocol. It was hypothesised that compression garments would 15 attenuate perceived muscle soreness and elicit a faster recovery of strength and other 16 physiological measures relative to the control condition. 


\section{Materials and Methods}

\section{Participants}

3 Ten healthy male participants (mean $\pm \mathrm{SD}, 23 \pm 3 \mathrm{yrs}, 180.8 \pm 6.4 \mathrm{~cm}, 80.8 \pm 9.8 \mathrm{~kg}$ )

4 volunteered to partake in this study. All participants were physically active (typically 5 exercising at least three times per week in either team sport or resistance exercise activities)

6 and had 1-2 years experience working in manual labour occupations (construction,

7 landscaping, warehouse duties). However, not all participants had undertaken labour-oriented

8 work in the recent months, and thus all were appropriately familiarised with the physical

9 demands of the study. Following an explanation of the testing protocol, all participants gave

10 written informed consent to engage in testing procedures, with ethical approval granted by

11 the University Human Research Ethics Committee.

\section{Research Design}

14 Participants completed two testing sessions consisting of control (CON; no compression 15 garments) and experimental; compression (COMP; long sleeve compression top and short leg 16 pants) conditions. Respective conditions were performed in a manner consistent with a randomised 17 cross-over experimental design, and there was a minimum of one week between the two testing sessions. A 4-h manual labour exercise protocol was performed on both occasions, with perceptual, physiological and physical tests undertaken before, immediately following and 24

20 h post-exercise.

22 Participants were required to avoid alcohol ingestion, caffeine and strenuous exercise in the

$2324 \mathrm{~h}$ prior to testing, and were provided with a standardised pre-exercise meal which was 24 consumed $3.5 \mathrm{~h}$ prior to each testing session. The carbohydrate $(\mathrm{CHO})$ intake for this meal 
1 was calculated using nutritional information found on product labelling and nutritional

2 software was used to quantify the $\mathrm{CHO}$ value of fruit portions (Foodworks v.7, Xyris

3 software, Brisbane, Australia). Meals were individualised based on the participant's body

4 mass $(2.5 \mathrm{~g} \mathrm{CHO} / \mathrm{kg}$ body mass), and standardised to ensure uniform nutritional intake prior

5 to each testing session. In both conditions, during the exercise protocol participants wore

6 industry standard work clothing consisting of a cotton drill long sleeve top and full length

7 pants (King Gee, Pacific Brands, Melbourne, Australia). For the experimental condition,

8 participants also wore a long sleeve compression top (full length) and short leg pants (mid-

9 thigh length) (KingGee, Pacific Brands, Melbourne, Australia), underneath the work clothing

10 and were provided with another set to wear in the $24 \mathrm{~h}$ following the exercise. Compression

11 garments were fitted according to manufacturer guidelines based on body size and

12 anthropometrical characteristics. The exact level of compression was not measured in this

13 study, which is noted as a limitation. The compressive long-top and shorts were selected due

14 to the likelihood of similar garments being worn in an industrial workplace. Compression

15 garments were not worn during any part of the pre or post-exercise testing procedures.

\section{Exercise Protocol}

18 Using research quantifying activities undertaken by individuals working in construction and 19 mining industries (Hartmann and Fleischer, 2005; Maiti, 2008; van der Molen et. al. 2005), 20 an exercise protocol was created to simulate the workload of manual labour tasks. The 21 exercise protocol consisted of a circuit of 10 stations, with participants completing two 22 circuits to total $4 \mathrm{~h}$ of physical work (Table 1). Participants completed 9 min of continuous 23 exercise at each station followed by $3 \mathrm{~min}$ of standing recovery (Kenny et al. 2012). The 24 exercises were repetitive in nature and required participants to manipulate and transport 25 moderate-heavy loads or engage in awkward postures e.g. squatting and overhead lifting, as 
1 these movements were identified as being characteristic of physical labour occupations

2 (Hartmann and Fleischer 2005; van der Molen et al. 2005; Maiti 2008). Prior to the first

3 testing session, participants were familiarised with the testing procedures and performed one

4 circuit $(2 \mathrm{~h})$ of the exercise protocol. Participants were provided with $1.2 \mathrm{~L}$ of water and $0.6 \mathrm{~L}$

5 of sports drink (Gatorade, $6 \% \mathrm{CHO}, 22 \mathrm{mmol} / \mathrm{L} \mathrm{Na}$ ) to fully consume ad libitum during the

6 4-h protocol. The exercise protocol was performed in an indoor gymnasium at an ambient

7 temperature of $25.4 \pm 5.5^{\circ} \mathrm{C}$ and $73.0 \pm 12.5 \%$ relative humidity.

9 Experimental Procedures

10 Prior to, following and $24 \mathrm{~h}$ after the exercise protocol, participants underwent a range of

11 perceptual, physical and physiological tests to assess fatigue and recovery from the exercise

12 protocol. Stature was measured during the familiarisation session using a stadiometer

13 (Holtain, Crosswell, United Kingdom). At each testing session, participants were instructed

14 to void their bladder and record nude body mass (Lightever, Kunshan City, China). Core

15 body temperature was measured via a telemetric capsule (Equivital, Mini Mitter, USA) which

16 was ingested $3.5 \mathrm{~h}$ prior to testing. Core body temperature was recorded on the testing day,

17 prior to, halfway through and immediately after the exercise protocol, but not $24 \mathrm{~h}$ post

18 exercise. Participants wore a heart rate monitor throughout the exercise protocol (Polar

19 Electro, Oy, Finland) and heart rate was recorded at the end of the exercise period at each

20 respective station.

Perceptual Measures

23 Participants completed a Brunel Mood State Questionnaire (BRUMS) Terry et. al. (2003) to

24 assess mood state. The questionnaire consists of 24 mood descriptors, which correspond to 6

25 sub-categories (anger, tension, depression, confusion, vigour, fatigue). Using a 5 point Likert 
1 scale $(0=$ not at all, $1=$ a little, $2=$ moderately, $3=$ quite a bit, $4=$ extremely $)$ participants

2 gave a rating for each mood descriptor to give a score out of 16 for each subcategory. From 3 these measures, particular attention was paid to the subscales of anger, vigour and fatigue, as

4 these factors contribute to workplace productivity and employee well-being (Colligan et al. 5 2006).

7 Rating of perceived muscle soreness (MS) was determined using an 11 point Likert scale $(0=$ 8 no soreness or normal; $3=$ uncomfortable; $5=$ sore; $8=$ very sore; $10=$ extremely sore or 9 maximum soreness). Participants performed three shoulder rolls and half squats prior to each 10 measurement and gave separate scores for upper and lower body muscle soreness (Duffield 11 and Portus 2007). Rating of Perceived Exertion (RPE) was measured using Borg's category12 ratio scale $(0=$ rest; $10=$ maximal), which is frequently used to subjectively assess level of 13 exercise intensity, also referred to as Borg's CR-10 RPE scale (Borg 1990). An RPE score 14 was recorded immediately after the 4-h exercise protocol as a subjective measure of the 15 session intensity (session RPE) (Wallace et al. 2009).

\section{Muscle damage and blood inflammatory markers}

18 A $10 \mathrm{~mL}$ sample of venous blood was collected from the antecubital vein into serum separator 19 tubes via venepuncture following $10 \mathrm{~min}$ of seated rest. Blood samples were left standing for $2010 \mathrm{~min}$ before being centrifuged at $4000 \mathrm{rpm}$ for $10 \mathrm{~min}$. The serum from the samples was 21 aliquoted into Eppendorf containers (Eppendorf, Germany) and frozen at $-20^{\circ} \mathrm{C}$ for later 22 analysis. The serum samples were defrosted to room temperature before undergoing a series 23 of chemical and enzymatic reactions to ascertain creatine kinase $(\mathrm{CK})$ and $\mathrm{C}$-reactive protein 24 (CRP) concentration (P-800 Module-Photometric, Roche Diagnostics, Japan). The coefficient 25 of variation for the CK analysis was $1.16-1.36 \%$ and $3.25-5.13 \%$ for CRP. 
$1 \quad$ Muscle Stiffness

2 Passive muscle stiffness readings were obtained with a myometer device (MyotonPro,

3 Myoton, Tallinn, Estonia) which assesses the viscoelastic properties (measured in N.m ${ }^{-1}$ ) of

4 the muscle. All muscle stiffness measures were obtained from the right side of the body using

5 anthropometric landmarks to ensure a standardised measurement site for all testing sessions

6 (Bizzini and Manion 2003). Three upper body muscles: biceps brachii, triceps brachii and

7 trapezius, along with one lower body muscle (rectus femoris) were measured. The

8 measurement sites for biceps and triceps were located on the anterior and posterior aspects of

9 the upper arm, midway between the acromion process and head of radius. Trapezius muscle

10 stiffness was assessed midway between $\mathrm{C} 7$ and the acromion process. All upper body muscle

11 stiffness measurements were recorded with the participant standing with their arms in a

12 relaxed position by their side. Muscle stiffness for rectus femoris was assessed in a quasi-

13 active state with the participant standing with their weight distributed evenly between both

14 feet and also in a passive state with the participant lying down in a supine position. The

15 testing site was located midway between the inguinal line and superior aspect of the patella.

16 Three stiffness measures were obtained at each site via the delivery of a mechanical

17 perturbation, with the resultant damped oscillations recorded by an in-built accelerometer

18 sampling at $3200 \mathrm{~Hz}$. The mean of three measures was used for each location.

Strength Measures

21 Maximal wrist flexor strength of the right hand was assessed using a handgrip dynamometer

22 (TTM, Tokyo, Japan). Hand grip strength is a test commonly used to assess upper limb

23 function (Innes 1999). Given the large component of manual handling in physical labour

24 tasks, this test was selected for its relevance to manual labour exercise. Participants stood

25 with their back against a wall, holding the dynamometer in a vertical position above their 
1 head. In a controlled movement, participants would swing their arm downwards in a $180^{\circ}$ arc,

2 while simultaneously squeezing the dynamometer. Participants performed two maximal 3 efforts, with 30 seconds rest between each effort. The highest score was used for subsequent 4 analysis (Incel et al. 2002).

6 Peak torque for knee flexion and extension was assessed using an isokinetic dynamometer

7 (Biodex System 3, Shirley NY, USA). Participants were seated in an upright position with 8 hip and knee angles set at $90^{\circ}$; the dynamometer arm was positioned so its axis was in line 9 with the centre of the knee joint and secured via Velcro straps. The participant's left leg and 10 upper body were also secured via Velcro straps to prevent extraneous movement. Knee 11 extension torque was measured as the peak force generated as the knee moved from $90^{\circ}$ to 12 full extension; and knee flexion torque was measured as the peak force generated as the lower 13 leg returned to the starting position (McCleary and Anderson 1992). Participants were 14 instructed to maximally contract throughout the entire phase of each movement. One set 15 consisted of three repetitions with the dynamometer set at an angular velocity of $60^{\circ} \cdot \mathrm{sec}^{-1}$. A warm up set was performed at submaximal intensity with $60 \mathrm{~s}$ rest followed by the test where

17 maximal exertion was required. The highest value achieved during one single repetition of 18 these maximal efforts was used for data analysis.

Standardised response to exercise

21 Participants performed a standardised workload as follows: 4 min of sub-maximal work $22(175 \mathrm{~W})$ on a cycle ergometer (Wattbike, Nottingham, UK) followed by $1 \mathrm{~min}$ of seated 23 recovery. This protocol was performed to assess acute exercise induced fatigue. Participants 24 wore a heart rate monitor (Polar Electro, Oy, Finland) to measure heart rate (HR) which was 25 recorded in the final $15 \mathrm{~s}$ of the cycling protocol $\left(\mathrm{HR}_{4 \mathrm{~min}}\right)$ and following $1 \mathrm{~min}$ of seated 
1 recovery $\left(\mathrm{RHR}_{1 \mathrm{~min}}\right)$. Borg's CR-10 RPE scale was used to record an RPE score at the end of

2 the 4 min of cycling to provide a subjective rating of the exercise performed $\left(\mathrm{RPE}_{4} \mathrm{~min}\right)$.

\section{$4 \quad$ Statistical Analysis}

5 All data are reported as mean $\pm \mathrm{SD}$ and analyses were performed using Statistical Package

6 for the Social Sciences version 21 (Chicago, IL, USA). Within- and between-condition and

7 time-point differences were assessed using two-way repeated measures ANOVA (condition $\mathrm{x}$

8 time). Post hoc analysis to determine the location of differences when a significant main

9 effect or interactions were detected were performed using a paired $t$ test with Tukey's

10 adjustment within conditions over time and between conditions at each time point. An alpha

11 level of 0.05 was used for all statistical procedures. Effect size analysis using Cohen's $d$ was

12 used to determine the magnitude of difference between control and COMP conditions for all

13 corresponding variables. Effect size data representing the magnitude of difference was

14 categorised accordingly: trivial, $d<0.19$; small, $0.20 \leq d \leq 0.39$, moderate $0.40 \leq d \leq 0.79$;

15 large, $d \geq 0.80$ (Cohen, 1988).

\section{Results}

\section{Physiological variables}

19 Physiological responses to the 4-h simulated labouring protocol for both conditions and 20 comparative effect size data are presented in Table 2 . The within-condition change for body 21 mass indicated a significant post-exercise reduction $(\mathrm{p}<0.05)$ in both conditions, which had 22 returned to baseline values by $24 \mathrm{~h}$ post. No significant difference $(\mathrm{p}>0.05)$ and trivial effect 23 sizes were evident between conditions for body mass. Similarly, core body temperature 24 showed a significant increase following the exercise protocol in both conditions $(\mathrm{p}<0.05)$, 
1 though no significant difference $(\mathrm{p}>0.05)$ and trivial-small effect sizes were observed

2 between conditions. Mean HR during the simulated labouring protocol was not significantly

3 different between conditions ( $p>0.05)$, alongside trivial effect sizes.

4 Creatine Kinase concentrations increased significantly in both conditions at post and $24 \mathrm{~h}$

5 post exercise $(\mathrm{p}<0.05)$. However, no significant differences $(\mathrm{p}>0.05)$ and small-moderate

6 effect sizes were evident between conditions. Additionally, no significant within- or between-

7 group differences $(\mathrm{p}>0.05)$ were present for CRP, with trivial-moderate effect sizes evident

8 between conditions.

\section{Muscle strength and stiffness}

11 Muscle strength and stiffness measures are presented in Table 3. No significant differences

12 were found within or between conditions for maximal hand grip strength or knee flexion 13 torque ( $>0.05$ ), with trivial-small effect sizes evident between conditions immediately and $1424 \mathrm{~h}$ post-exercise. Maximum knee extension torque was reduced $(\mathrm{p}<0.05)$ in both conditions 15 following the exercise protocol, but returned to baseline values by $24 \mathrm{~h}$ post. The increase 16 from post to $24 \mathrm{~h}$ was only found to be significant within the CON condition $(3.1 \pm 5.4 \%$ 17 change, $\mathrm{p}<0.05)$; but not COMP condition $(2.2 \pm 11.1 \%$ change, $\mathrm{p}>0.05)$. Between conditions, 18 significant difference $(\mathrm{p}<0.05)$, and trivial-small effect sizes were observed for knee 19 extension torque; with post-hoc analysis showing a significant increase $(7.9 \% \pm 14.5)$ between 20 post and $24 \mathrm{~h}$ post measures in the CON condition.

22 A significant time interaction effect was observed for quadriceps (lying) muscle stiffness in 23 both conditions with a decrease in stiffness between pre and post-exercise measures (Control: $24-6.9 \pm 4.6 \%, \mathrm{p}<0.05$; COMP: $-5.8 \pm 6.4 \%, \mathrm{p}<0.05)$. For $24 \mathrm{~h}$ post measures, stiffness increased 25 from post-exercise but did not return to baseline values. In the CON condition, this reduction 
1 from pre-exercise values $(-4.6 \pm 5.8 \%)$ was found to be significant $(\mathrm{p}<0.05)$, but was not for

2 the COMP condition $(-2.9 \pm 4.6 \%, \mathrm{p}>0.05)$. Similarly, significant differences were found for

3 the decrease in triceps stiffness post-exercise in the COMP condition $(-6.3 \pm 5.2 \% ; \mathrm{p}<0.05)$,

4 but not in the CON condition $(-1.4 \pm 8.0 \%)$.

6 Between condition analysis revealed a significant difference for triceps muscle stiffness

$7 \quad(\mathrm{p}<0.05)$. Post-hoc analysis revealed that the COMP condition yielded a significant $6.3 \pm 5.9 \%$

$8 \quad(\mathrm{p}<0.05)$ decrease between pre-post exercise values, compared to a negligible $(1.4 \pm 7.98 \%$;

$9 \mathrm{p}>0.05)$ change in $\mathrm{CON}$ condition. No significant differences and trivial-small effect sizes

10 were evident for all other muscle stiffness measures; though a moderate effect size $(d=0.55)$

11 was evident for higher trapezius muscle stiffness $24 \mathrm{~h}$ post exercise in the control condition.

\section{Perceptual measures}

14 The results for muscle soreness, perceived anger, fatigue, vigour and RPE for the $4 \mathrm{~h}$ 15 simulated labouring protocol for both conditions and comparative effect size data are 16 presented in Table 4. A significant time interaction effect was evident in both conditions with 17 an increase in both upper and lower body muscle soreness $(p<0.05)$. Between condition 18 analysis found no significant difference $(\mathrm{p}>0.05)$, yet moderate-large effect sizes $(d=0.59$ -

19 0.88) were evident for increased upper body MS and moderate effect sizes $(d=0.45-0.53)$ for

20 lower body MS post and $24 \mathrm{~h}$ post-exercise in the compression condition. In both conditions,

21 perceived fatigue increased significantly immediately following and $24 \mathrm{~h}$ after the exercise 22 protocol $(\mathrm{p}<0.05)$. Between conditions, there was no significant difference and moderate 23 effect sizes for perceived fatigue $(d=0.44-0.72)$. No significant differences were evident 24 within or between conditions for perceived anger and vigour with trivial-moderate effect 
1 sizes between conditions. Session RPE was not significantly different $(\mathrm{p}<0.05)$ and trivial

2 effect sizes were observed between conditions.

3

$4 \quad$ Standardised response to exercise

5 Table 5 presents HR and RPE data recorded after 4-min cycling and 1-min seated recovery

6 performed pre, post and $24 \mathrm{~h}$ post exercise. $\mathrm{HR}_{4 \min }$ and $\mathrm{RHR}_{1 \mathrm{~min}}$ were significantly higher

7 following the exercise protocol in both conditions $(\mathrm{p}<0.05)$, though returned to baseline

8 values by $24 \mathrm{~h}$ post. The RPE measured after 4 min of cycling was significantly higher

$9 \quad(\mathrm{p}<0.05)$ following the $4 \mathrm{~h}$ labouring protocol exercise in the CON condition, though not in

10 the COMP condition ( $\mathrm{p}>0.05)$. However at $24 \mathrm{~h}$ post, $\mathrm{RPE}_{4 \mathrm{~min}}$ had returned to baseline levels

11 in both conditions ( $\mathrm{p}>0.05)$. No significant difference was found between conditions for any

12 variables assessed during the cycling protocol. Moderate effect sizes were found for $\mathrm{RPE}_{4 \mathrm{~min}}$

13 at post and $24 \mathrm{~h}$ post time points, and for $\mathrm{RHR}_{1 \mathrm{~min}}$ at the $24 \mathrm{~h}$ post exercise time point

14 (d=0.51). All $\mathrm{HR}_{4 \min }$ measurements and post exercise $\mathrm{RHR}_{1 \min }$ were trivial-small in effect 15 size. 


\section{Discussion}

2 The purpose of this study was to investigate the influence of compression garments on the

3 physiological and perceptual responses to, and recovery following prolonged manual labour.

4 Though not statistically significant, moderate-large effects were demonstrated for reduced

5 perceptual measures of muscle soreness and fatigue immediately and $24 \mathrm{~h}$ following exercise,

6 and perceived exertion of 4-min cycling in the compression condition. A significant

7 difference was observed for peak knee extension torque between conditions $(p<0.05)$, with

8 higher post and $24 \mathrm{~h}$ post values in the $\mathrm{CON}$ condition. However, no differences were evident

9 for any other force production measure or physiological response to exercise between

10 conditions. Accordingly, it appears that wearing compression garments during and following

11 a simulated prolonged manual labour protocol may improve perceptual measures of recovery

12 and perceived work readiness.

14 The simulated manual labour protocol used in the current study was physically demanding to

15 replicate the type of manual workload regularly undertaken by industrial-based workers

16 (Hartmann and Fleischer 2005; Maiti 2008). Following the exercise protocol, there was an

17 increase in $\mathrm{CK}$ concentration, perceived level of fatigue and perceived muscle soreness,

18 indicating the exercise protocol was of an adequate physical load and intensity to induce

19 muscular damage and fatigue observed in industrial worksites (Hartmann and Fleischer 2005;

20 Kraemer et al. 2010; Jakobsen et al. 2014). Participants rated the exercise protocol as "hard"

21 on the Borg CR-10 RPE scale, which is reflective of high muscular loading experienced

22 during manual labour tasks (Jakobsen et al. 2014).

24 Despite the demands mentioned above, there were no decrements for hand grip strength or 25 peak knee flexion torque observed following the exercise protocol and no difference between 
1 conditions. Knee extension torque decreased following the exercise protocol, increased at the

$224 \mathrm{hr}$ time point to exceed baseline values in the CON condition. The lack of observed

3 change in peak force production may have been a factor limiting the ability of compression to

4 improve muscular function. Whilst manual labour is of low intensity, movements are

5 repetitive and performed over a prolonged period of time; and consequently result in a large

6 volume of muscular work (van der Molen et al. 2005). As this was the first study to assess the

7 influence of compression on manual labour exercise, it can now be confirmed that

8 compression has no effect on handgrip strength following this type of exercise. These

9 findings support previous research where compression has only been found to be effective in

10 the restoration of muscular force in studies of maximal eccentric work or where a high level

11 of muscle damage has occurred (Duffield and Portus 2007; Gill et al. 2006; Kraemer et al.

12 2001a; Kraemer et al. 2001b)

14 The manual labour protocol resulted in an increase in CK concentrations following exercise;

15 however, no differences were observed between conditions at any time point. This result is 16 consistent with the research where many studies report no changes in CK concentration when 17 compression is applied post-exercise (Davies et al. 2009; Duffield et al. 2008; Pruscino et al. 18 2013). In other physiological measures, no differences were evident between conditions for 19 heart rate and core body temperature during the 4-h exercise protocol. These findings are in 20 agreement with (MacRae et al. 2012), who reported compression garments had minimal 21 effect on cardiac variables and core body temperature during a standardised cycling protocol 22 (60-min fixed load cycling and $6 \mathrm{~km}$ time trial). MacRae et. al. (2012) suggested that 23 compression had minimal influence on cardiovascular function during exercise as circulatory 24 function is already optimised during dynamic exercise. 
1 Further, the application of compression in medical contexts has been found to enhance blood

2 circulation and venous return in clinical populations, and be most effective when applied to

3 the lower limb (Agu et al. 1999; Lawrence and Kakkar 1980). Enhancing venous return may

4 be beneficial to recovery via improvement in metabolite removal and increased circulation to

$5 \quad$ limbs (Berry and Murray 1987; Chatard et al. 2004). One of the limitations of this study was

6 the length of mid-thigh level compression shorts worn by participants, which could have

7 potentially limited the efficacy of the compression intervention. Although the short length of

8 the shorts may limit compression, the reality of full-length compression garments being worn

9 in mining/labouring industries is unlikely, thus the current apparel was chosen. Accordingly,

10 the effect of compression on manual labour exercise via full length compression tights or calf

11 socks remains an area for further research. Further, although the compression garments were

12 fitted to participants according to manufacturer's recommendations, it has been reported that

13 compression applied via sport compression garments is variable according to sizing and

14 posture (Brophy-Williams et. al., 2014) It is acknowledged that a limitation of this study is

15 that the level of compression was not measured.

17 Muscle stiffness represents the amount of stiffness residing within the muscle-tendon unit and 18 affects the rate of force development (Brughelli and Cronin 2008; Wilson et al. 1991). In this 19 study, muscle stiffness decreased following the exercise protocol, potentially as a result of the 20 exercise-induced increase in body temperature and changes to musculotendinous properties 21 following 4-h manual labour exercise (Brughelli and Cronin 2008; Ditroilo et al. 2011). 22 Wearing compression garments during and $24 \mathrm{~h}$ post-exercise, was only found to affect the 23 triceps musculature, while no difference was observed for other muscles measured. Given the 24 trivial-small effect of compression on stiffness response observed in other muscles, it is 25 possible that the style of compression garments, being long-sleeved, specifically affected the 
1 triceps. Furthermore, many of the activities in the exercise protocol (see Table 1) involved a

2 muscular contraction of the triceps muscle, i.e. lifting, carrying, pushing resulting in a large

3 load on this muscle group. The difference in triceps stiffness following recovery may have

4 been due to a higher degree of muscle fatigue and subsequent greater magnitude for

5 improvement given the smaller muscle capacity and heightened activation of triceps in the 6 exercise protocol for lifting activities.

8 In the current study, compression demonstrated moderate-large effects on improved 9 perceptual measures of fatigue, muscle soreness and recovery. Specifically, a moderate effect on perceived muscle soreness post-exercise and large effect for reduced upper body muscle soreness $24 \mathrm{~h}$ post-exercise was observed in the compression condition. Whilst there was a

12 trend for higher muscle soreness in the control condition at baseline, this difference was not 13 significant $(\mathrm{p}>0.05)$. Consequently, caution is warranted when interpreting these results.

14 Previous literature has reported a common trend for reduced perceived muscle soreness from 15 wearing compression garments for post exercise recovery (Davies et al. 2009; Duffield et al. 2008; Duffield et al. 2010; Jakeman et al. 2010; Pruscino et al. 2013). Wearing compression

17 had a moderate effect on perceived fatigue and perceived exertion for the 4-min cycling test 18 performed post-exercise. These findings agree with previous research where lower levels of 19 fatigue, improved vitality and enhanced recovery were reported when compression garments 20 were worn following exercise (Kraemer et al. 2000; Pruscino et al. 2013). Additionally, 21 (Kraemer et al. 2000) demonstrated that wearing compression hosiery was beneficial in mediating discomfort of the lower limbs elicited from $8 \mathrm{~h}$ of prolonged standing. Given the 23 predominance of prolonged standing for work duties in industrial worksites (Halim and Omar 24 2011), compression may be useful in alleviating perceived discomfort and fatigue, and 25 potentially enhance work readiness and productivity for manual labour workers (Kraemer et 
1 al. 2000). However, in the absence of participants being blinded to the compression

2 condition, a placebo effect from the compression condition cannot be excluded as influencing

3 perceptual responses (Duffield et al. 2008; Duffield et al. 2010; Pruscino et al. 2013).

4

5 Finally, in the current study, fatigue and recovery were assessed after one 4-h session of

6 work. It is possible over consecutive work shifts and higher volumes of work, compression

7 could demonstrate a greater effect on testing measures. (Montgomery et al. 2008) reported

8 that wearing compression post-exercise during a three day basketball tournament had

9 moderate-large effect on improving perceived fatigue and muscle soreness relative to passive

10 recovery. It is recognised that a one-off 4-h shift does not represent the consecutive day and

$11 \quad 8-12 \mathrm{~h}$ duration shift of many manual labourers. The exercise protocol utilised in the current

12 study was successful in using manual labour tasks to elicit the physical demands of an

13 industrial workplace, and the findings demonstrate the role of compression to improve

14 perceptual responses to fatigue and muscle soreness. Future research should investigate the

15 effect of compression over a longer period of time and consecutive days or shifts, which will

16 allow the effect of cumulative fatigue to be assessed.

\section{Conclusion}

19 Compression garments had minimal influence on performance or recovery from a 4-h manual

20 labour exercise protocol. Although there were no differences in strength or physiological

21 parameters, compression garments appeared to have a positive moderate-large effect on

22 perceptual measures in the recovery period following the exercise protocol, though was not

23 statistically significant. Despite the possibility of a placebo effect, use of compression was

24 effective in reducing levels of perceived muscle soreness, perceptual fatigue and ratings of

25 exertion during subsequent exercise workloads. These outcomes may benefit manual labour 
1 workers in improving their work readiness, by decreasing perceived fatigue and perception of 2 physical work and muscle soreness.

3

\section{Acknowledgements}

5 The authors would like to acknowledge Pacific Brands for providing the funding and 6 compression garments for the project. Additionally the authors wish to thank the participants 7 and research assistants involved with the project. Furthermore the authors wish to thank

8 Professor Aaron Coutts for his assistance with the study. This research investigation was 9 carried out in compliance with the ethical laws of Australia and the authors have no conflicts 10 of interest that are relevant to the content of this article. The results of the present study do 11 not constitute endorsement of the product by the authors. 


\section{Reference List}

2

3

4

5

6

7

8

9

10

11

12

13

14

15

Agu, O., Hamilton, G., and Baker, D. 1999. Graduated compression stockings in the prevention of venous thromboembolism. British Journal of Surgery 86(8): 992-1004.

Ali, A., Caine, M., and Snow, B. 2007. Graduated compression stockings: physiological and perceptual responses during and after exercise. Journal of Sports Sciences 25(4): 413-419.

Bahnert, A., Norton, K., and Lock, P. 2013. Association between post-game recovery protocols, physical and perceived recovery, and performance in elite Australian Football League players. Journal of Science and Medicine in Sport 16(2): 151-156.

Berry, M.J. and McMurray, R.G. 1987. Effects of graduated compression stockings on blood lactate following an exhaustive bout of exercise. American Journal of Physical Medicine and Rehabilitation 66(3): 121-132.

Bizzini, M. and Mannion, A.F. 2003. Reliability of a new, hand-held device for assessing skeletal muscle stiffness. Clinical Biomechanics 18(5): 459-461.

Borg, G. 1990. Psychophysical scaling with applications in physical work and the perception of exertion. Scandinavian Journal of Work, Environment and Health 16: 55-58.

Brophy-Williams, N., Driller, M. W., Shing, C. M., Fell, J. W. and Halson, S. L. (2014). Confounding compression: the effects of posture, sizing and garment type on measured interface pressure in sports compression clothing. Journal of Sports Sciences (ahead-of-print), $1-8$.

Brughelli, M. and Cronin, J. 2008. A review of research on the mechanical stiffness in running and jumping: methodology and implications. Scandinavian Journal of Medicine and Science in Sports 18(4): 417-426.

Chang, F.-L., Sun, Y.-M., Chuang, K.-H., and Hsu, D.-J. 2009. Work fatigue and physiological symptoms in different occupations of high-elevation construction workers. Applied Ergonomics 40(4): 591-596.

Chatard, J.-C., Atlaoui, D., Farjanel, J., Louisy, F., Rastel, D., and Guezennec, C.-Y. 2004. Elastic stockings, performance and leg pain recovery in 63-year-old sportsmen. European Journal of Applied Physiology 93(3): 347-352.

Colligan, T. W., and Higgins, E. M. (2006). Workplace stress: Etiology and consequences. Journal of Workplace Behavioral Health 21(2), 89-97.

Davies, V., Thompson, K.G., and Cooper, S.-M. 2009. The effects of compression garments on recovery. The Journal of Strength and Conditioning Research 23(6): 1786-1794.

Ditroilo, M., Watsford, M., and De Vito, G. 2011. Validity and inter-day reliability of a freeoscillation test to measure knee extensor and knee flexor musculo-articular stiffness. Journal of Electromyography and Kinesiology 21(3): 492-498. 
1 Duffield, R., Cannon, J., and King, M. 2010. The effects of compression garments on recovery of muscle performance following high-intensity sprint and plyometric exercise. Journal of Science and Medicine in Sport 13(1): 136-140.

Duffield, R., Edge, J., Merrells, R., Hawke, E., Barnes, M., Simcock, D., and Gill, N. 2008. The effects of compression garments on intermittent exercise performance and recovery on consecutive days. International Journal of Sports Physiology and Performance 3(4): 454-468.

Duffield, R. and Portus, M. 2007. Comparison of three types of full-body compression garments on throwing and repeat-sprint performance in cricket players. British Journal of Sports Medicine 41(7): 409-414.

Gill, N., Beaven, C., and Cook, C. 2006. Effectiveness of post-match recovery strategies in rugby players. British Journal of Sports Medicine 40(3): 260-263.

Halim, I. and Omar, A.R. 2011. A review on health effects associated with prolonged standing in the industrial workplaces. International Journal of Research and Review in Applied Science 8(1): 14-21.

Hartmann, B. and Fleischer, A.G. 2005. Physical load exposure at construction sites. Scandinavian Journal of Work, Environment and Health: 88-95.

Incel, N.A., Ceceli, E., Durukan, P.B., Erdem, H.R., and Yorgancioglu, Z.R. 2002. Grip strength: effect of hand dominance. Singapore Medical Journal 43(5): 234-237.

Innes, E. 1999. Handgrip strength testing: A review of the literature. Australian Occupational Therapy Journal 46(3): 120-140.

Jakeman, J.R., Byrne, C., and Eston, R.G. 2010. Lower limb compression garment improves recovery from exercise-induced muscle damage in young, active females. European Journal of Applied Physiology 109(6): 1137-1144.

Jakobsen, M.D., Sundstrup, E., Persson, R., Andersen, C.H., and Andersen, L.L. 2014. Is Borg's perceived exertion scale a useful indicator of muscular and cardiovascular load in blue-collar workers with lifting tasks? A cross-sectional workplace study. European Journal of Applied Physiology 114(2): 425-434.

Kenny, G.P., Vierula, M., Maté, J., Beaulieu, F., Hardcastle, S.G., and Reardon, F. 2012. A field evaluation of the physiological demands of miners in Canada's deep mechanized mines. Journal of Occupational and Environmental Hygiene 9(8): 491-501.

Kraemer, W.J., Bush, J.A., Wickham, R.B., Denegar, C.R., Gómez, A.L., Gotshalk, L.A., Duncan, N.D., Volek, J.S., Putukian, M., and Sebastianelli, W.J. 2001. Influence of compression therapy on symptoms following soft tissue injury from maximal eccentric exercise. Journal of Orthopaedic and Sports Physical Therapy 31(6): 282-290.

Kraemer, W.J., Flanagan, S.D., Comstock, B.A., Fragala, M.S., Earp, J.E., Dunn-Lewis, C., Ho, J.-Y., Thomas, G.A., Solomon-Hill, G., and Penwell, Z.R. 2010. Effects of a whole body compression garment on markers of recovery after a heavy resistance workout in men and women. The Journal of Strength and Conditioning Research 24(3): 804-814. 
1

2

3

4

5

6

7

8

9

10

11

12

13

14

Kraemer, W.J., Volek, J.S., Bush, J.A., Gotshalk, L.A., Wagner, P.R., Gomez, A.L., Zatsiorsky, V.M., Duzrte, M., Ratamess, N.A., and Mazzetti, S.A. 2000. Influence of compression hosiery on physiological responses to standing fatigue in women. Medicine and Science in Sports and Exercise 32(11): 1849-1858.

Lawrence, D. and Kakkar, V. 1980. Graduated, static, external compression of the lower limb: a physiological assessment. British Journal of Surgery 67(2): 119-121.

MacRae, B.A., Laing, R.M., Niven, B.E., and Cotter, J.D. 2012. Pressure and coverage effects of sporting compression garments on cardiovascular function, thermoregulatory function, and exercise performance. European Journal of Applied Physiology 112(5): 17831795.

Maiti, R. 2008. Workload assessment in building construction related activities in India. Applied Ergonomics 39(6): 754-765.

McCleary, R.W. and Andersen, J. 1992. Test-retest reliability of reciprocal isokinetic knee extension and flexion peak torque measurements. Journal of Athletic Training 27(4): 362.

McPhee, B. 2004. Ergonomics in mining. Occupational Medicine 54(5): 297-303.

Montgomery, P.G., Pyne, D.B., Hopkins, W.G., Dorman, J.C., Cook, K., and Minahan, C.L. 2008. The effect of recovery strategies on physical performance and cumulative fatigue in competitive basketball. Journal of Sports Sciences 26(11): 1135-1145.

Parida, R. and Ray, P.K. 2011. A comprehensive framework for physical evaluation of manual material handling tasks. International Journal of Manufacturing Technology and Management 24(1): 153-166.

Pruscino, C.L., Halson, S., and Hargreaves, M. 2013. Effects of compression garments on recovery following intermittent exercise. European Journal of Applied Physiology 113(6): 1585-1596.

Terry, P.C., Lane, A.M., and Fogarty, G.J. 2003. Construct validity of the Profile of Mood States-Adolescents for use with adults. Psychology of Sport and Exercise 4(2): 125-139.

van der Molen, H.F., Sluiter, J.K., Hulshof, C.T., Vink, P., and Frings-Dresen, M.H. 2005. Effectiveness of measures and implementation strategies in reducing physical work demands due to manual handling at work. Scandinavian Journal of Work, Environment and Health 31(s2): 75-87.

Wallace, L.K., Slattery, K.M., and Coutts, A.J. 2009. The ecological validity and application of the session-RPE method for quantifying training loads in swimming. The Journal of Strength and Conditioning Research 23(1): 33-38.

Wilson, G., Wood, G., and Elliott, B. 1991. The relationship between stiffness of the musculature and static flexibility: an alternative explanation for the occurrence of muscular injury. International Journal of Sports Medicine 12(04): 403-407. 


\section{TABLES}

2 Table 1 Exercise protocol, sequence and equipment list for the simulated manual labour 3 protocol. Each station was 9 minutes in duration $/ 3$ min rest.

4

\begin{tabular}{|c|c|c|c|}
\hline Station & Load & Instructions & Workload \\
\hline $\begin{array}{l}\text { Stairs } \\
\text { (50 stairs total) }\end{array}$ & $2 \times 10 \mathrm{~kg}$ weight plates & $\begin{array}{l}\text { Start at top of the stairs, walk } \\
\text { down, take stairs up two at a time. } \\
\text { Carry weight plates in each hand. }\end{array}$ & $\begin{array}{l}\text { One effort } \\
\text { every min }\end{array}$ \\
\hline Log weight carry & $2 \times 15 \mathrm{~kg} \log$ weights & Carry log weights and walk $40 \mathrm{~m}$. & $\begin{array}{l}\text { One effort } \\
\text { every min }\end{array}$ \\
\hline Shelf Stacking & $\begin{array}{l}3 \times 6.5 \mathrm{~kg} \text { boxes } \\
\text { Place on boxes } \\
30,45 \text { and } 60 \mathrm{~cm} \text { high }\end{array}$ & $\begin{array}{l}\text { Pick up weight off box, squat } \\
\text { down and put on the ground. } \\
\text { Move to the next box and repeat. } \\
\text { Once all the boxes are off, put } \\
\text { them back on. }\end{array}$ & $\begin{array}{l}\text { One effort } \\
\text { every } 30 \mathrm{sec}\end{array}$ \\
\hline Tyre stack & $\begin{array}{l}4 \mathrm{x} \text { tyres } \\
\text { Total weight } 15.6 \mathrm{~kg}\end{array}$ & $\begin{array}{l}\text { Pick up two tyres, hold at chest } \\
\text { height so they are horizontal, walk } \\
20 \mathrm{~m} \text {. }\end{array}$ & $\begin{array}{l}\text { One effort } \\
\text { every } 30 \mathrm{sec}\end{array}$ \\
\hline Sledgehammering & $\begin{array}{l}\text { Sledgehammer } \\
\text { Tyre stack (1.2 m high) } \\
\text { Sledgehammer } 12 \mathrm{~kg}\end{array}$ & $\begin{array}{l}\text { Hit tyres with sledgehammer, start } \\
\text { hammer at hip height. Hit at a } \\
\text { consistent rate and force. }\end{array}$ & $\begin{array}{l}\text { Continuous } \\
10 \text { hits } \\
\text { every } 30 \mathrm{sec}\end{array}$ \\
\hline Vibration platform & $\begin{array}{l}\text { Continuous half } \\
\text { squats or calf raises } \\
\text { for } 1 \mathrm{~min}\end{array}$ & $\begin{array}{l}\text { Perform half squats and calf raises } \\
\text { with feet shoulder width apart, } \\
\text { Vibration platform set to } 26 \mathrm{~Hz} \text {. }\end{array}$ & $\begin{array}{l}\text { One effort every } \\
\text { min with } \\
30 \text { sec rest }\end{array}$ \\
\hline
\end{tabular}

$\begin{array}{llll}\text { Box carrying } & 2 \mathrm{x} \text { boxes } & \text { Pick up two boxes, walk with } & \begin{array}{l}\text { One effort } \\ \text { Total weight } 33 \mathrm{~kg}\end{array} \\ & \text { boxes for } 60 \mathrm{~m} . & \end{array}$

\begin{tabular}{llll}
\hline Overhead lifting & $1 \times 10 \mathrm{~kg}$ weight plate & $\begin{array}{l}\text { Hold } 10 \mathrm{~kg} \text { weight plate above } \\
\text { head - keep arms slightly bent, } \\
\text { elbows pointing forward. }\end{array}$ & $\begin{array}{l}\text { One effort every } \\
\text { min with } \\
30 \mathrm{sec} \text { rest }\end{array}$ \\
\hline Trolley & $\begin{array}{l}\text { Total loadincluding } \\
\text { trolley } 70 \mathrm{~kg}\end{array}$ & $\begin{array}{l}\text { Push loaded trolley up and down } \\
\text { ramp in a controlled manner. } \\
\text { Ascend ramp walking backwards. }\end{array}$ & $\begin{array}{l}\text { One effort } \\
\text { every } 30 \mathrm{sec}\end{array}$ \\
\hline Heavy Rope Pull & $\begin{array}{l}\text { Rope gather } \\
(10 \mathrm{~m} x 10 \mathrm{~cm} \\
\text { thickness, } 15 \mathrm{~kg})\end{array}$ & $\begin{array}{l}\text { Lay rope out to full length then } \\
\text { pull the entire length of rope in. }\end{array}$ & $\begin{array}{l}\text { One effort } \\
\text { every } 30 \mathrm{sec}\end{array}$ \\
\hline
\end{tabular}


1 Table 2: Body mass, core temperature, heart rate, creatine kinase and C-reactive protein for

2 Control vs. Compression Garment condition at pre, post and $24 \mathrm{~h}$ post-exercise (values are 3 mean $\pm \mathrm{SD})$.

\begin{tabular}{|c|c|c|c|c|c|}
\hline Variable & & $\begin{array}{l}\text { Control } \\
(n=10)\end{array}$ & $\begin{array}{l}\text { Compression } \\
\quad(\mathrm{n}=10)\end{array}$ & $\begin{array}{r}\text { Effect Size } \\
\text { (Cohen's } d \text { ) }\end{array}$ & $\begin{array}{c}\text { Condition } \\
\text { main effect } \\
\text { p value }\end{array}$ \\
\hline \multirow{3}{*}{$\begin{array}{l}\text { Body Mass } \\
\text { (kg) }\end{array}$} & Pre & $80.68 \pm 9.83$ & $80.82 \pm 9.82$ & 0 & \multirow{3}{*}{0.49} \\
\hline & Post & $79.83 \pm 9.75^{*}$ & $79.79 \pm 9.70^{*}$ & 0 & \\
\hline & $24 \mathrm{hr}$ & $80.56 \pm 9.66^{\#}$ & $80.72 \pm 9.83^{\#}$ & 0 & \\
\hline \multirow{3}{*}{$\begin{array}{l}\text { Core Temp } \\
\quad\left({ }^{\circ} \mathrm{C}\right)\end{array}$} & Pre & $36.9 \pm 0.2$ & $36.9 \pm 0.2$ & 0 & \multirow{3}{*}{0.80} \\
\hline & During & $37.6 \pm 0.4^{*}$ & $37.4 \pm 0.5$ & 0.10 & \\
\hline & Post & $37.7 \pm 0.4^{*}$ & $37.5 \pm 0.4^{*}$ & 0.30 & \\
\hline \multirow{3}{*}{ 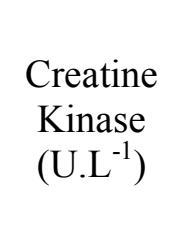 } & Pre & $207 \pm 96$ & $267 \pm 146$ & 0.48 & \multirow{3}{*}{0.88} \\
\hline & Post & $368 \pm 117^{*}$ & $435 \pm 222^{*}$ & 0.38 & \\
\hline & $24 \mathrm{hr}$ & $313 \pm 118^{*}$ & $363 \pm 187^{*}$ & 0.32 & \\
\hline \multirow{3}{*}{$\begin{array}{l}\text { C-reactive } \\
\text { protein } \\
\left(\mathrm{U} . \mathrm{L}^{-1}\right)\end{array}$} & Pre & $0.42 \pm 0.21$ & $0.78 \pm 0.66$ & 0.69 & \multirow{3}{*}{0.45} \\
\hline & Post & $0.43 \pm 0.22$ & $0.73 \pm 0.56$ & 0.69 & \\
\hline & $24 \mathrm{hr}$ & $1.09 \pm 1.19$ & $1.21 \pm 0.77$ & 0.13 & \\
\hline $\begin{array}{c}\mathrm{HR}_{\text {Exercise }} \\
\text { (bpm) }\end{array}$ & During & $129 \pm 13$ & $129 \pm 11$ & 0 & 0.99 \\
\hline
\end{tabular}

$5 *$ significantly different from pre-exercise time point within same condition $(\mathrm{p}<0.05)$.

6 \# significantly different from post-exercise time point within same condition $(\mathrm{p}<0.05)$. 
1 Table 3: Muscle strength and stiffness for Control vs. Compression Garment condition taken 2 pre, post and $24 \mathrm{~h}$ post exercise (values are mean $\pm \mathrm{SD}$ )

3

\begin{tabular}{|c|c|c|c|c|c|}
\hline Variable & & $\begin{array}{l}\text { Control } \\
(n=10)\end{array}$ & $\begin{array}{l}\text { Compression } \\
\qquad(\mathbf{n}=10)\end{array}$ & $\begin{array}{l}\text { Effect Size } \\
\text { (Cohen's } d \text { ) }\end{array}$ & $\begin{array}{c}\text { Condition } \\
\text { main effect } \\
\text { p value }\end{array}$ \\
\hline \multirow{3}{*}{$\begin{array}{l}\text { Grip Strength } \\
(\mathrm{kg})\end{array}$} & Pre & $50.8 \pm 5.2$ & $53.4 \pm 7.5$ & 0.40 & \multirow{3}{*}{0.19} \\
\hline & Post & $48.7 \pm 5.3$ & $50.3 \pm 3.9$ & 0.36 & \\
\hline & $24 \mathrm{~h}$ & $51.4 \pm 5.7$ & $50.1 \pm 3.9$ & -0.26 & \\
\hline \multirow{3}{*}{$\begin{array}{l}\text { Knee flexion } \\
\text { peak torque } \\
(\mathrm{Nm})\end{array}$} & Pre & $140 \pm 13$ & $142 \pm 17$ & 0.15 & \multirow{3}{*}{0.14} \\
\hline & Post & $146 \pm 11$ & $139 \pm 21$ & -0.39 & \\
\hline & $24 \mathrm{~h}$ & $143 \pm 14$ & $139 \pm 16$ & -0.29 & \\
\hline \multirow{3}{*}{$\begin{array}{l}\text { Knee extension } \\
\text { peak torque } \\
(\mathrm{Nm})\end{array}$} & Pre & $272 \pm 34$ & $273 \pm 39$ & 0.03 & \multirow{3}{*}{$0.04^{\wedge}$} \\
\hline & Post & $269 \pm 43$ & $258 \pm 44$ & -0.27 & \\
\hline & $24 \mathrm{~h}$ & $277 \pm 42^{\#}$ & $266 \pm 41$ & -0.28 & \\
\hline \multirow{3}{*}{$\begin{array}{l}\text { Bicep Stiffness } \\
\left(\mathrm{N} \cdot \mathrm{m}^{-1}\right)\end{array}$} & Pre & $218 \pm 25$ & $221 \pm 21$ & 0.14 & \multirow{3}{*}{0.81} \\
\hline & Post & $209 \pm 22$ & $213 \pm 20$ & 0.23 & \\
\hline & $24 \mathrm{~h}$ & $211 \pm 19$ & $216 \pm 14$ & 0.34 & \\
\hline Triceps & Pre & $222 \pm 29$ & $227 \pm 30$ & 0.20 & \multirow{3}{*}{$0.00^{\wedge}$} \\
\hline Stiffness & Post & $221 \pm 38$ & $213 \pm 20^{*}$ & -0.24 & \\
\hline$\left(\mathrm{N} \cdot \mathrm{m}^{-1}\right)$ & $24 \mathrm{~h}$ & $229 \pm 33$ & $216 \pm 20$ & -0.49 & \\
\hline Trapezius & Pre & $322 \pm 50$ & $340 \pm 57$ & 0.33 & \multirow{3}{*}{0.24} \\
\hline Stiffness & Post & $325 \pm 35$ & $312 \pm 36$ & -0.37 & \\
\hline$\left(\mathrm{N} \cdot \mathrm{m}^{-1}\right)$ & $24 \mathrm{~h}$ & $312 \pm 43$ & $337 \pm 47$ & 0.55 & \\
\hline Standing Quad & Pre & $314 \pm 44$ & $332 \pm 95$ & 0.25 & \multirow{3}{*}{0.22} \\
\hline Stiffness & Post & $297 \pm 34$ & $296 \pm 42$ & -0.05 & \\
\hline$\left(\mathrm{N} . \mathrm{m}^{-1}\right)$ & $24 \mathrm{~h}$ & $315 \pm 49$ & $333 \pm 80$ & 0.27 & \\
\hline Lying Quad & Pre & $286 \pm 27$ & $284 \pm 39$ & -0.05 & \multirow{3}{*}{0.78} \\
\hline Stiffness & Post & $266 \pm 25^{*}$ & $267 \pm 34^{*}$ & 0.03 & \\
\hline$\left(\mathrm{N} \cdot \mathrm{m}^{-1}\right)$ & $24 \mathrm{~h}$ & $273 \pm 32^{* \#}$ & $276 \pm 39$ & 0.09 & \\
\hline
\end{tabular}

$4{ }^{*}$ significantly different from pre-exercise time point within same condition $(\mathrm{p}<0.05)$.

5 \# significantly different from post-exercise time point within same condition $(\mathrm{p}<0.05)$.

$6 \wedge$ significant difference between conditions $(\mathrm{p}<0.05)$. 
1 Table 4: Upper and lower body muscle soreness ${ }^{\wedge}$, perceived anger, fatigue and vigour levels 2 and session RPE for Control vs. Compression Garment condition taken pre, post and $24 \mathrm{~h}$ 3 post exercise (values are mean \pm SD)

\begin{tabular}{|c|c|c|c|c|c|}
\hline Variable & & $\begin{array}{l}\text { Control } \\
(n=10)\end{array}$ & $\begin{array}{l}\text { Compression } \\
\quad(\mathbf{n}=\mathbf{1 0})\end{array}$ & $\begin{array}{l}\text { Effect Size } \\
(\text { Cohen's } d)\end{array}$ & $\begin{array}{c}\text { Condition } \\
\text { main effect } \\
\text { p value }\end{array}$ \\
\hline & Pre & $1.2 \pm 1.5$ & $0.8 \pm 0.9$ & -0.32 & \\
\hline \multirow[t]{3}{*}{$\begin{array}{l}\mathrm{MS}_{\text {Upper }} \\
(0-10)\end{array}$} & Post & $5.1 \pm 2.0^{*}$ & $4.0 \pm 1.5^{*}$ & -0.59 & 0.52 \\
\hline & $24 \mathrm{~h}$ & $4.7 \pm 2.6^{*}$ & $2.6 \pm 1.8^{* \#}$ & -0.88 & \\
\hline & Pre & $1.7 \pm 1.7$ & $0.9 \pm 1.1$ & -0.54 & \\
\hline \multirow[t]{3}{*}{$\begin{array}{l}\mathrm{MS}_{\text {Lower }} \\
(0-10)\end{array}$} & Post & $4.5 \pm 1.2^{*}$ & $4.0 \pm 0.9 *$ & -0.45 & 0.07 \\
\hline & $24 \mathrm{~h}$ & $4.0 \pm 1.7^{*}$ & $3.1 \pm 1.8^{* \#}$ & -0.53 & \\
\hline & Pre & $0.2 \pm 0.6$ & $0.6 \pm 0.97$ & 0.49 & \\
\hline \multirow[t]{3}{*}{$\begin{array}{l}\text { Perceived } \\
\text { Anger (AU) }\end{array}$} & Post & $0.8 \pm 1.6$ & $0.4 \pm 0.97$ & -0.30 & 0.33 \\
\hline & $24 \mathrm{~h}$ & $0.7 \pm 1.5$ & $0.2 \pm 0.42$ & -0.44 & \\
\hline & Pre & $3.9 \pm 3.5$ & $2.5 \pm 2.6$ & -0.45 & \\
\hline \multirow[t]{3}{*}{$\begin{array}{l}\text { Perceived } \\
\text { Fatigue (AU) }\end{array}$} & Post & $7.7 \pm 2.0^{*}$ & $5.7 \pm 3.1^{*}$ & -0.72 & 0.83 \\
\hline & $24 \mathrm{~h}$ & $3.8 \pm 3.4^{\#}$ & $2.5 \pm 2.4^{\#}$ & -0.44 & \\
\hline & Pre & $8.6 \pm 4.2$ & $8.6 \pm 2.5$ & 0.00 & \\
\hline \multirow[t]{2}{*}{$\begin{array}{l}\text { Perceived } \\
\text { Vigour (AU) }\end{array}$} & Post & $6.5 \pm 3.8$ & $6.4 \pm 4.7$ & -0.02 & 0.82 \\
\hline & $24 \mathrm{~h}$ & $7.8 \pm 3.2$ & $8.9 \pm 2.8$ & 0.36 & \\
\hline $\begin{array}{l}\mathrm{RPE}_{\text {Session }} \\
(\mathrm{AU})\end{array}$ & Post & $5.4 \pm 1.5$ & $5.3 \pm 1.3$ & -0.07 & 0.79 \\
\hline
\end{tabular}

$5 \wedge$ as stated in the Methods section, muscle soreness scale descriptors are as follows: $(0=$ no 6 soreness or normal; $3=$ uncomfortable; $5=$ sore; $8=$ very sore; $10=$ extremely sore or maximum 7 soreness).

$8 *$ significantly different from pre-exercise time point within same condition $(p<0.05)$.

9 \# significantly different from post-exercise time point within same condition $(\mathrm{p}<0.05)$. 
1 Table 5: Heart rate and RPE following 4 min cycling with 1 min recovery for Control vs.

2 Compression condition taken pre, post and $24 \mathrm{~h}$ post exercise (values are mean $\pm \mathrm{SD}$ )

3

\begin{tabular}{llcccc}
\hline Variable & & $\begin{array}{c}\text { Control } \\
(\mathbf{n}=\mathbf{1 0})\end{array}$ & $\begin{array}{c}\text { Compression } \\
(\mathbf{n}=\mathbf{1 0})\end{array}$ & $\begin{array}{c}\text { Effect Size } \\
\text { (Cohen's } \boldsymbol{d})\end{array}$ & $\begin{array}{c}\text { Condition } \\
\text { main effect } \\
\text { p value }\end{array}$ \\
\hline & Pre & $130 \pm 15$ & $130 \pm 14$ & -0.04 & \\
$\begin{array}{l}\mathrm{HR}_{4 \text { min }} \\
(\mathrm{bpm})\end{array}$ & Post & $141 \pm 20^{*}$ & $141 \pm 13^{*}$ & 0.06 & 0.63 \\
& $24 \mathrm{~h}$ & $134 \pm 14$ & $131 \pm 11^{\#}$ & -0.20 & \\
\hline $\begin{array}{l}\mathrm{RPE}_{4 \text { min }} \\
(0-10)\end{array}$ & Pre & $2.7 \pm 1.2$ & $2.6 \pm 1.0$ & -0.05 & \\
& $24 \mathrm{~h}$ & $3.0 \pm 1.0^{\#}$ & $2.6 \pm 0.5^{\#}$ & -0.43 & \\
\hline & Pre & $91 \pm 17$ & $89 \pm 15$ & -0.13 & \\
$\mathrm{RHR}_{1 \text { min }}$ & Post & $109 \pm 17^{*}$ & $108 \pm 18^{*}$ & -0.09 & 0.15 \\
$(\mathrm{bpm})$ & $24 \mathrm{~h}$ & $93 \pm 14^{\#}$ & $86 \pm 15^{\#}$ & -0.51 & \\
& & $3.9 \pm 1.1^{*}$ & $3.4 \pm 0.6$ & -0.55 & \\
\hline
\end{tabular}

$4{ }^{*}$ significantly different from pre-exercise time point within same condition $(\mathrm{p}<0.05)$.

5 \# significantly different from post-exercise time point within same condition $(\mathrm{p}<0.05)$.

$6 \quad \mathrm{HR}_{4 \min }=$ heart rate post 4 minutes of cycling, $\mathrm{RHR}_{1 \mathrm{~min}}=$ Recovery heart rate following $1 \mathrm{~min}$

7 of seated recovery, $\mathrm{RPE}_{4 \mathrm{~min}}=\mathrm{RPE}$ reported post 4 min cycling 